\title{
Research progress of low-temperature heat recovery technology in sulfuric acid production
}

\author{
Jianfang Zong,, Liang Sun, Huiting Guo and Fei Fang \\ China National Institute of Standardization, \\ No.4 Zhichun Road, Haidian Distrcit, Beijing
}

\begin{abstract}
Low-temperature waste heat refers to the sum of the heat degraded and transferred to the dry absorption process after the high- and medium-temperature heat is recovered in the conversion process in the conventional sulfuric acid production plant, as well as the sulfuric acid formation heat, steam condensation heat and sulfuric acid dilution heat generated in the dry absorption process. It is of great practical significance to rationally develop and utilize the low-temperature waste heat. This paper introduces the development of traditional waste heat recovery technology and low-temperature heat recovery technology for sulfur-based sulfuric acid production. It also expounds the principle, process technology and main equipment of developing low-temperature heat recovery technology for sulfuric acid production plants at home and abroad, and summarizes the low-temperature heat recovery technology for sulfuric acid production plants.
\end{abstract}

\section{Overview}

Sulfuric acid production itself is an exothermic process, including sulfur combustion, sulfur dioxide oxidation and sulfur trioxide absorption. At present, the high- and medium-temperature heat of sulfur-based sulfuric acid production in China is generally recovered, and the hightemperature heat of pyrite and smelting flue gas for sulfuric acid production is also generally recycled. However, due to the limitation of process conditions, most of the low-temperature waste heat, which accounts for nearly $25 \%$ of the total heat, has not been recycled. Low-temperature heat recovery technology for sulfuric acid production from sulfur is the highlight of energy conservation and consumption reduction in sulfuric acid industry in recent years. The technology can recover all the waste heat in the sulfuric acid production process to the greatest extent, and the heat recovery rate of sulfuric acid production from sulfur is increased from $60 \%$ $70 \%$ to more than $90 \%$, and the steam production per ton of sulfuric acid is increased from $1 \sim 1.2 \mathrm{t}$ to $1.7 \sim 1.8 \mathrm{t}$. According to incomplete statistics, currently, 16 sulfurbased sulfuric acid-making enterprises in China have been equipped with low-temperature waste heat recovery systems and put them into production with a scale of about 11.5 million tons; 18 enterprises with a capacity of about 10 million tons are to be equipped with lowtemperature waste heat recovery systems. In the future, 10 million tons of production capacity can be equipped with the system, and then the heat recovery rate of $80 \%$ of the production capacity for sulfuric acid production from sulfur will be increased to more than $90 \%$ [1].

\section{Traditional waste heat recovery process for sulfur-based sulfuric acid production}

The sulfuric acid production process in sulfuric acid enterprises contains very rich high-, medium- and lowtemperature heat resources. In the process of producing sulfuric acid by two conversions and two absorptions, the waste heat at $800 \sim 1000{ }^{\circ} \mathrm{C}$ in the sulfur incineration process is usually called high-temperature waste heat, accounting for $55 \%$ of the total waste heat; the waste heat at about $500{ }^{\circ} \mathrm{C}$ in the conversion process is called medium-temperature waste heat, accounting for $20 \%$ of the total waste heat; and the waste heat at about $100{ }^{\circ} \mathrm{C}$ in the dry absorption process is called low-temperature waste heat, accounting for $25 \%$ of the total waste heat [2]. High-temperature waste heat and mediumtemperature waste heat are relatively easy to recycle due to their high temperatures. Low-temperature waste heat has a low temperature, and acid temperature is related to acid concentration. In the sulphur-based sulphuric acid production process, the acid concentration of primary absorption, secondary absorption and dry acid are all $98 \%$, and the acid temperature is about $100{ }^{\circ} \mathrm{C}$. Due to the difficulty of recovery, most sulfuric acid manufacturers have not recovered the low-temperature waste heat. Generally, the generated acid with lowtemperature waste heat flows through the acid cooler to exchange heat with the cold circulating water to cool down. This not only does not utilize the low-temperature waste heat, but also needs to use a large amount of

\footnotetext{
* Corresponding author: zongjf@enis.ac.cn
} 
cooling water to reduce the temperature of the acid, wasting both energy and water.

\section{Development of low-temperature heat recovery technology}

Generally speaking, there are three forms of utilization of low-temperature waste heat in sulfuric acid production plants: firstly, heating other materials, such as preheating boiler feed water, heating domestic and industrial water, heating papermaking liquid, and concentrating sulfuric acid, phosphoric acid, etc.; secondly, using materials with a low boiling point as carriers to drive turbine generator sets to generate electricity; thirdly, adopting high temperature absorption to produce low pressure steam and increase power generation.

\subsection{Heating process materials with low - temperature waste heat}

The chemical company Boliden in Helsingborg, Sweden has three pyrite-based sulfuric acid plants with capacities of $560 \mathrm{t} / \mathrm{d}, 750 \mathrm{t} / \mathrm{d}$ and $750 \mathrm{t} / \mathrm{d}$ respectively. To utilize the low-temperature waste heat of the acid circulation system, the company successfully installed the world's largest urban hot water heating devices and water supply systems from 1978 to 1980 .In order to prevent possible leakage of acid coolers, such systems usually use soft water as an intermediate heat carrier for indirect heat exchange. The designed soft water pressure is greater than the sulfuric acid side pressure and lower than the heating water pressure, and the $\mathrm{pH}$ value and conductivity of desalted water are continuously measured [3-6].

Each of Boliden's above three sets of devices has a soft water circulation system. The soft water first passes through the finished acid with lower acid temperature or the circulating acid cooler of the drying tower. After passing through an acid cooler connected in parallel with the final absorption tower in the middle, the soft water is heated to $92{ }^{\circ} \mathrm{C}$, and then enters the heat exchange station to heat the heating water to $88{ }^{\circ} \mathrm{C}$. If the weather is cold, it needs to be heated to $110-115{ }^{\circ} \mathrm{C}$ by the oilfired boiler in the city center or by low-pressure steam. And the excess heat needs to be removed by cooling water in summer. Two sets of $280 \mathrm{kt} / \mathrm{a}$ sulfuric acid production plants in Dayukou, Hubei Province, China adopt Monsanto process technology, and simultaneously heat desalted water, industrial water and domestic water by using the low-temperature waste heat of the dryabsorption circulating acid system. The acid cooler is a stainless steel acid cooler with anodic protection. The acid temperature at the inlet of the acid cooler in the drying tower is $80.6{ }^{\circ} \mathrm{C}$, and the acid temperature at the inlet of the acid cooler in the absorption tower is $108.8{ }^{\circ} \mathrm{C}$. The closed-circuit circulation soft water system is used to transfer heat, heating desalted water from $25{ }^{\circ} \mathrm{C}$ to $90{ }^{\circ} \mathrm{C}$, the hot water for mineral processing from $25{ }^{\circ} \mathrm{C}$ to $75{ }^{\circ} \mathrm{C}$, and the domestic heating water from $52{ }^{\circ} \mathrm{C}$ to $75{ }^{\circ} \mathrm{C}$.

As for using low-temperature waste heat of sulfuric acid production plant to heat the process medium, besides the above applications, there are many specific applications, such as flotation of phosphate ore, leaching of uranium ore, heating of electrolytic cells for copper refining, preheating of solution for zinc refining, heating of ammonia and phosphoric acid in ammonium phosphate production, heating of titanium dioxide production and seawater desalination. The lowtemperature heat of sulfuric acid production plant belongs to low-level energy, with low quality and less effective energy. Therefore, its application is limited. Only by improving its quality can it break through the limitation of application. Since the plate heat exchanger and anode-protected shell-and-tube acid cooler were popularized in industry in the 1970s, the heat of circulating acid in the absorption tower can be used to produce hot water at $80-95{ }^{\circ} \mathrm{C}$ and to heat other materials. However, because the hot water is at a low temperature of and only its sensible heat can be utilized, the utilization of this part of heat is greatly limited.

\subsection{Using working medium with a low boiling point as the carrier to drive turbine generator set to generate electricity}

With the application of low boiling point media, lowtemperature heat can be used to generate electricity. If freon turbine steam is used for power circulation, its heat source can adopt $80-90{ }^{\circ} \mathrm{C}$ hot water, $120-130{ }^{\circ} \mathrm{C}$ low pressure steam or $200-300{ }^{\circ} \mathrm{C}$ flue gas, but its theoretical efficiency is only $8 \%-14 \%$, and the power generation capacity of $1 \mathrm{GJ} / \mathrm{h}$ heat is only $23.9-35.8 \mathrm{~kW} / \mathrm{h}$. Propane, a low boiling point medium, is also used as a working medium to generate propane steam, which is superheated and then drives a steam turbine to generate electricity.

As the heat transfer performance of low boiling point media is usually poor, when operating under the conditions of low heat transfer temperature and heat load, the required heat transfer area is often very large, resulting in the consumption of a large amount of expensive metals. In addition, low boiling point media are often flammable, explosive and toxic, so the system has high sealing requirements. Therefore, feasibility study and technical and economic comparison should be carried out when using low-temperature waste heat to heat low boiling point media for waste heat power generation design.

\subsection{Production of low pressure steam by using low-temperature waste heat}

Generally, the absorption process of a sulfuric acid production plant is as follows: After the $\mathrm{SO}_{2}$ flue gas is converted into $\mathrm{SO}_{3}$ by the converter, it enters the bottom of the absorption tower. The upper part of the tower is sprayed with concentrated sulfuric acid with $\mathrm{w}\left(\mathrm{H}_{2} \mathrm{SO}_{4}\right)$ $\geq 98 \%$. The $\mathrm{SO}_{3}$ in the moisture flue gas in the concentrated sulfuric acid reacts to generate sulfuric acid 
(i.e. being absorbed by concentrated sulfuric acid), which increases the concentration of the sprayed concentrated sulfuric acid. At the same time, because the reaction is exothermic, the acid temperature of the concentrated sulfuric acid also increases. Concentrated sulfuric acid absorbing $\mathrm{SO}_{3}$ in flue gas is discharged from the bottom of the tower to the acid circulation tank. Appropriate water is added into the tank to dilute the sulfuric acid to the concentration before entering the absorption tower, and then the sulfuric acid is sent to the acid cooler by the acid circulation pump for cooling. The cooled concentrated sulfuric acid (the acid temperature is generally lower than $80{ }^{\circ} \mathrm{C}$ ) then enters the top of the absorption tower for spraying. In this cycle, the reaction heat generated by absorbing $\mathrm{SO}_{3}$ is taken away by circulating water in the acid cooler and wasted.

In order to generate steam with the above-mentioned low-temperature waste heat, the temperature of circulating acid must be further increased, but the corrosivity of sulfuric acid also increases with the increase of its temperature, which is also the most important factor limiting the recovery of lowtemperature heat to generate medium-pressure steam. Therefore, the selection of materials resistant to corrosion of high-temperature concentrated sulfuric acid is a key to the low-temperature heat recovery system, including materials used in the equipment, acid pipelines, valves, pump bodies, etc. It should be noted that the sulfuric acid in the whole circulating acid system must be strictly controlled at $\mathrm{w}\left(\mathrm{H}_{2} \mathrm{SO}_{4}\right) \geq 99 \%$, so as to ensure the corrosion resistance and long-term stable operation of system equipment and pipelines.

It is necessary to ensure that the $\mathrm{w}\left(\mathrm{H}_{2} \mathrm{SO}_{4}\right)$ of the absorption acid entering the tower is about $99 \%$, because too high a concentration of the acid will seriously affect the absorption efficiency of $\mathrm{SO}_{3}$, or the heat recovery efficiency of the low-temperature heat recovery system.

As the absorption rate of sulfur trioxide is relatively reduced under the conditions of high temperature and high absorption acid concentration, the process gas after absorption at high temperature must be further absorbed by sulfuric acid with relatively lower temperature and concentration to ensure the absorption efficiency of the whole absorption process. Therefore, the absorption process is usually divided into two parts: high temperature absorption and low temperature absorption, which can be completed in one plant or set separately.

As for the high-temperature absorption part, the temperature of the circulating acid is greatly increased, the steam generator is used instead of the acid cooler to produce low-pressure steam, i.e., the reaction heat in the absorption process is used to generate low-pressure steam. And the concentrated sulfuric acid mixer, boiler feed water heater and desalted water heater are added at the outlet of the steam generator, thus greatly improving the heat recovery rate of the sulfuric acid production plant. Using low-temperature heat recovery technology, the steam production per ton of sulfuric acid is $0.40-0.52$ $\mathrm{t}$, thus increasing the waste heat recovery rate of sulfuric acid production plant from the traditional $50 \%-70 \%$ to more than $90 \%$.

\section{Development of low-temperature heat recovery technology in foreign countries}

Low-temperature heat recovery technology has been developed and applied internationally for more than 20 years. Monsanto of the United States, Lurgi of Germany and Chemetics of Canada have all successfully developed the technology. The principle is to increase the circulating acid temperature of the absorption system and generate low-pressure steam by absorption reaction heat. The technical feature of German Lurgi is to use the high-temperature Venturi absorption tower already used by the company to generate high-temperature sulfuric acid at $170-220{ }^{\circ} \mathrm{C}$, which is introduced into the boiler to generate saturated steam. Chemetics of Canada uses lowtemperature waste heat to generate low-pressure saturated steam of $0.1 \mathrm{MPa}$ (gauge pressure). The HRS (Heat Recovery System) technology of US Monsanto has been widely used. The HRS developed by Monsanto consists of a heat recovery tower with a two-stage packing layer, an acid tank and circulating pump, a kettle boiler, an acid diluter and a boiler feed water preheater. The heat recovery tower replaces the first absorption tower in the two-conversion and two-absorption process, and $\mathrm{w}$ of the sulfur $\left(\mathrm{H}_{2} \mathrm{SO}_{4}\right)$ flowing out from the bottom of the tower is $99.5 \%-99.9 \%$, at $200-220{ }^{\circ} \mathrm{C}$, and $\mathrm{w}$ $\left(\mathrm{H}_{2} \mathrm{SO}_{4}\right)$ of the sulfur returning to the heat recovery tower after heat recovery and dilution by the boiler is controlled at $99.0 \%$.Low-temperature sulfuric acid with w $\left(\mathrm{H}_{2} \mathrm{SO}_{4}\right)$ of $98.5 \%$ drawn from the circulation system of the final absorption tower enters the upper part of the heat recovery tower to ensure higher absorption rate.

\section{Development of low-temperature heat recovery technology in China}

The low-temperature heat recovery system includes a high-temperature absorption tower, a high-temperature circulating acid pump, a steam generator, a mixer, a boiler feed water heater, etc. The primary conversion gas from the conversion system enters from the bottom of the high-temperature absorption tower, and the hightemperature concentrated sulfuric acid with $\mathrm{w}\left(\mathrm{H}_{2} \mathrm{SO}_{4}\right)$ about $99 \%$ sprays from the top of the tower to absorb $\mathrm{SO}_{3}$. The gas then enters the low-temperature absorption tower. The high-temperature concentrated sulfuric acid after absorbing sulfur trioxide flows into the hightemperature circulating acid pump tank, and then is sent to the steam generator by the high-temperature circulating acid pump to heat the boiler feed water to generate low-pressure steam. After the acid temperature is reduced, the sulfuric acid enters the mixer, mixes with water to adjust $\mathrm{w}\left(\mathrm{H}_{2} \mathrm{SO}_{4}\right)$ to about $99 \%$, and then enters the high-temperature absorption tower for circulation. Excess high-temperature concentrated sulfuric acid is led out from the outlet of the steam generator and sent to the acid circulation tank of the dry absorption tower after being cooled by the boiler feed water heater. A desalted water preheater can also be connected in series after the 
boiler feed water heater to further recover the heat in sulfuric acid in the acid circulation tank of the dry absorption tower. The absorption process of the lowtemperature absorption tower is the same as that of the traditional absorption tower to further absorb the remaining $\mathrm{SO}_{3}$ and remove acid mist. The gas absorbed by the high and low temperature absorption towers is then removed to the conversion system for secondary conversion.

\section{Introduction of main equipment}

\subsection{Heat recovery tower}

Heat recovery tower is the main equipment for lowtemperature heat recovery. It is a vertical cylindrical packed tower made of special stainless steel (with excellent corrosion resistance within the design temperature and sulfuric acid concentration range). The equipment does not need lining. The usual heat recovery tower is divided into two sections. The first section at the bottom is a high-temperature absorption section, using high-temperature concentrated sulfuric acid to absorb sulfur trioxide in flue gas and generate a large amount of heat. The upper section is a low-temperature absorption section, which is used to cool the flue gas and further remove the remaining sulfur trioxide. A large amount of acid mist generated by the absorption process is removed by a fiber demister arranged at the top of the tower.

\subsection{Steam generator}

Steam generator is a key device in the low-temperature heat recovery system. The steam-water circulation system adopts natural circulation mode. It is required that the device should not only have the high efficiency and good structural design of the boiler itself, but also have extremely high corrosion resistance. At the same time, reliable safety protection and interlocking system should be set up to ensure the long-term, reliable and stable operation of the device. The heat exchange tube of the steam generator is made of special stainless steel. High-temperature concentrated sulfuric acid is used inside the tube, and water is used outside the tube. Heat is transferred from sulfuric acid inside the tube to boiler water outside the tube, so that the water evaporates to generate steam. The steam generator consists of a tube box, a tube plate, a tube bundle, a tube body and a steam-water separation device.

\subsection{Mixer}

Low-temperature heat recovery technology sets up a special sulfuric acid mixer behind the steam generator to fully mix the added water with high-temperature concentrated sulfuric acid. As the process of adding water into concentrated sulfuric acid is very intense and releases a large amount of heat, the corrosion is especially serious, so the design of mixer and the selection of materials are very strict, requiring not only the even dispersion of added water, but also good corrosion resistance at high temperature.

\section{Conclusion}

With the development of modern society, the demand for energy is increasing. While developing new energy sources and adjusting the energy structure, efforts should be made to improve energy utilization efficiency and develop new energy-saving technologies, which are important issues to be solved at present. In the whole production process of sulfuric acid, energy is always generated. It should be realized that the sulfuric acid production plant is a green energy plant, which can not only produce sulfuric acid products, but also generate a large amount of high-, medium- and low-temperature heat. With the shortage of energy supply and the intensification of market competition, it is increasingly necessary to recover low-temperature heat in sulfuric acid production to improve the economic viability of enterprises. The technology has extensive demonstration significance in energy conservation and emission reduction, and also plays an important role in promoting energy system optimization, technological progress and cleaner production in the same industry.

\section{References}

1. Wang Huaili, Application Research on Waste Heat Grading Recovery Technology of Sulfuric Acid Plant Based on Low Temperature Heat Utilization, Shandong Chemical Industry, 2014 (43): 134-137.

2. Zhang Chaolin, Energy Saving and Emission Reduction in China's Sulfuric Acid Industry, Modern Chemical Industry, 2008, 28 (1): 12-17.

3. Liu Jizhuang and Wu Qinghuan, Heat Recovery and Utilization of Large Sulfur-based Sulfuric Acid Plants, Sulfuric Acid Industry, 2008 (6): 49-53.

4. Sun Zhengdong, Design of Super Large Sulfurbased Sulfuric Acid Plant, Sulfuric Acid Industry, 2007 (1): 15-24.

5. Chen Ziling, Yuan Yafei, Industrial Introduction of 3000t/d Sulfur-based Sulfuric Acid Plant, Sulphur Phosphorus and Bulk Materials Handling Related Engineering, 2006 (3): 16-19.

6. Tao Junfa, Development Direction of Sulfuric Acid Phosphate Fertilizer Industry in Yunnan, Phosphate and Compound Fertilizer, 2007 (2): 9-12. 